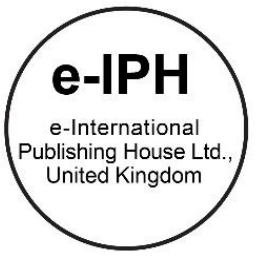

\title{
Influence of Social Behaviors toward Cultural Heritage Sustainability in World Heritage Site, Melaka
}

\author{
Nur Izzati Mohd Rodzi ${ }^{\star}$, Saniah Ahmad Zaki, Syed Mohd Hassan Syed Subli \\ Faculty of Architecture, Planning and Surveying, Universiti Teknologi MARA, 40450 Shah Alam, Malaysia
}

\begin{abstract}
Cultural heritage is constructed from the intrinsic relationship between three fundamentals: society; tangible cultural heritage (TCH); and intangible cultural heritage (ICH). To sustain, cultural heritage relies on the social behavior of society. Thus, reflecting fragility of heritage. Hence, this paper attempts to discourse the society's behavior towards $\mathrm{ICH}$. Exploratory case study was employed by adapting five social behavior related-criterions required by UNESCO. The data was analysed using two techniques: (1) simple statistical; and (2) thematic. The results indicate that the status of ICH is threatened due to the weak viability level and minimal safeguarding effort by the 'society'.

(C) 2016. The Authors. Published for AMER ABRA by e-International Publishing House, Ltd., UK. Peer-review under responsibility of AMER (Association of Malaysian Environment-Behaviour Researchers), ABRA (Association of Behavioural Researchers on Asians) and cE-Bs (Centre for Environment-Behaviour Studies, Faculty of Architecture, Planning \& Surveying, Universiti Teknologi MARA, Malaysia.
\end{abstract}

Keywords: Social behavior; intangible cultural heritage; world heritage site, threatened

\section{Introduction}

Cultural heritage is a symbiotic relationship involving society, norms and values. These are the pillars, the triangle relationship to form a smart partnership to sustain cultural heritage (Munjeri, 2004). On the other hand, symbols, technologies and objects are tangible evidence of fundamental norms and values (Bouchenaki, 2003). This two (2) statements show the inevitable association between Tangible Cultural Heritage (TCH) and Intangible Cultural Heritage (ICH) in envisioning the cultural shape and significance towards the community or society. The characteristic of $\mathrm{ICH}$ that relies on $\mathrm{TCH}$ and the possessors reflects the vulnerability of the elements. As the conservation of TCH is positively achieved, the effort of safeguarding $\mathrm{ICH}$ seems missing. The finding in a study by Othman and Hamzah (2013) has confirmed that the preservation and safeguarding effort of ICH is less emphasise in the MWHS. Figure 1 is an illustration on the association of the individual, community, and society, with cultural heritage. These components are important variables of this research.

\footnotetext{
${ }^{*}$ Corresponding author. Tel.: +6019-691-4564

E-mail address: nurizzatirodzi@gmail.com
} 


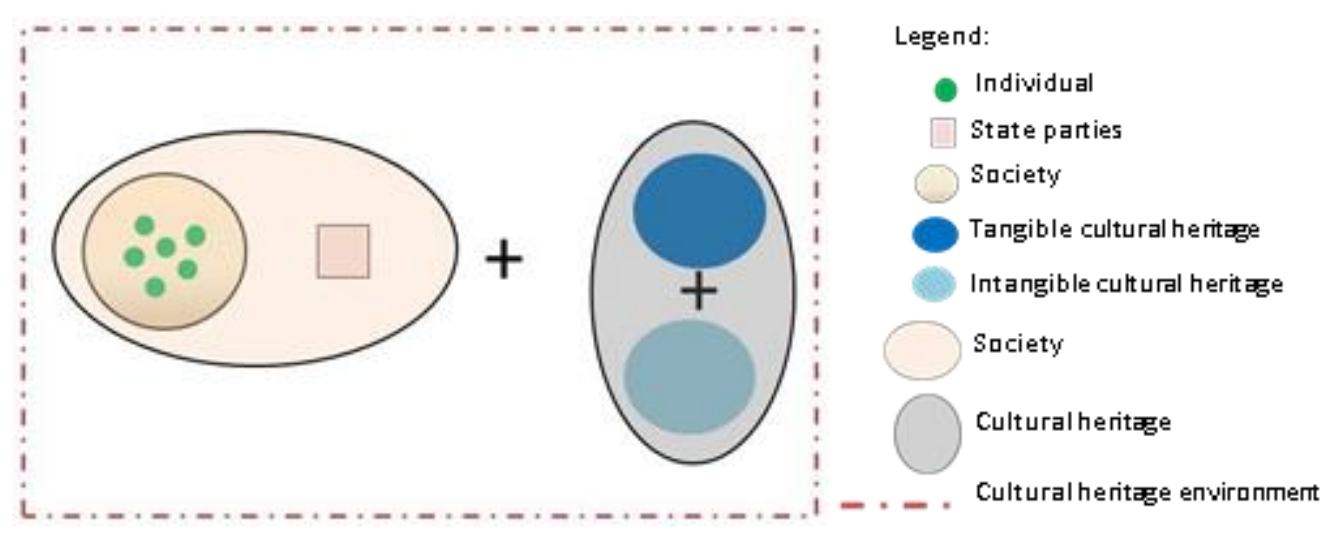

Fig. 1. Association of components in cultural heritage

Melaka nominated, as World Heritage Site on 2008, comprises of three (3) criteria of Outstanding Universal Values (OUV). One of the criterions is concerning Melaka as the most complete surviving historic cities in the Straits of Malacca with a multicultural living heritage originating from the trade routes at that time (ICOMOS, 2008). The term 'living heritage' as stated in the justification of the OUV criteria (criterion iii) is a proof of the extraordinary and unique existence of ICH value on the site. Therefore, this paper intends to discourse the society behavior against ICH at Core Zone, Melaka World Heritage Site. The research questions, firstly, what the subsist ICH in the study area, and secondly, what the status of $\mathrm{ICH}$ within the study area.

\section{Research Methodology}

Research methodology is important to determine the research idea and concept that is worth pursuing (Congdon \& Dunham, 1999). Therefore, to achieve the aim of this research, researchers set up three (3) mechanisms in its methodology. The mechanisms are: 1) research approach; 2) research instrument and 3) data analysis procedure. In order to achieve the research aim, adaptation of five (5) criterions (4 of the criterions are related to social-behavior) required by UNESCO, as stated in 'Urgent Safeguarding List' is necessary to be included in each stage of the methodology. These criterions later used as indicator in ICH status evaluation in the analysis stage. The five (5) criterions are:

- Criterion 1 - The element constitutes Intangible Cultural Heritage as defined in Article 22 of the Convention

- Criterion 2 - a) The element is in urgent need of safeguarding because its viability is at risk despite the efforts of the community, group or, if applicable, individuals and State(s) Party(ies) concerned; (or) b) The element is in extremely urgent need of safeguarding because it is facing grave threats as a result of which it cannot be expected to survive without immediately safeguarding.

- Criterion 3 - Safeguarding measures are elaborated that may enable the community, group or, if applicable, individuals concerned to continue the practice and transmission of the element

- Criterion 4 - The element has been nominated following the widest possible participation of the community, group or, if applicable, individuals concerned and their free, prior and informed consent.

- Criterion 5 - The element is included in an inventory of the intangible cultural heritage present in the territory (ies) of the submitting State(s) Party (ies), as defined in Article $11^{3}$ and Article $12^{4}$.

\subsection{Research approach}

The first component of research approach is case study oriented research. According to CAPAM (2010), there are three types of case study in conventional approach, they are: 1) illustrative case study; 2) exploratory case study and 3) explanatory case study. The researchers decided to employ exploratory case study because this type best describes a study that attempts to understand what happen within the case by looking beyond descriptive features and investigate surrounding context. The second research approach is utilization of mixed method. This method was applied in the field of cultural anthropologist as well as sociologist for the first 60 years of the 20th century (Johnson, Onwuegbuzie, \& Turner, 2007). 


\subsection{Research instrument}

Research instrument is a mechanism to elicit data needed as determined in the preliminary stage of research design. The importance of research instrument is to ensure information obtained fulfill the research data requirement. There are three (3) types of data instrument utilized in this research, which are:

- Site observation and inventory - According to Powell and Steele (2014) there are few reasons to utilised this tool such as: 1) when need direct information; 2) when written or other data collection procedure seem inappropriate; 3) when trying to understand an ongoing behaviour, process; 4) unfolding situation or event and looking for physical evidence; and 5) product or outcome that is able to be seen. Site observation and inventory attempted is to fulfill the criterion 1.

- Face to face questionnaire survey - According to Szolnoki and Hoffman (2013), face-to-face questionnaire survey is clearly structured, flexible and adaptable. The fundamental of this type of survey is on the personal interaction and ability to control the survey environment. As the main mechanism of data collection, this questionnaire survey was designed to achieve the criterion 2, 3 and 4 .

- Structured professional interview - Professional interview is the third tool of data collection in this research. Interview is a formal technique whereby researcher solicits verbal evidence or data from a knowledgeable informant (Remenyi, 2011). This professional interview transcript is designed to achieve the criterion 5.

\subsection{Data analysis procedure}

Data analysis will assist to support and answer the research questions. Therefore, there are two (2) types of data analysis procedure engaged in this research. The data procedures are: 1) frequency distribution and cross tabulation by using SPSS; and 2) thematic analysis.

\subsection{Limitation of the research}

Limitation according to Simon and Goes () are matters that emerge in the research, which is beyond the researcher's control. The limitations occurred in this research were: 1) inconsistency responses by targeted respondents; 2) limited professionals' involvement during data collection phases; and 3) time-constraints.

\section{Result}

\subsection{Criterion 1 - identification of the subsist ICH}

Based on the site observation and inventory, there are 815 buildings (including lots) available in the research area. From the statistical analysis, 599 (73.5\%) buildings out of 815 are occupied, 32 (3.9\%) buildings are under renovation and $184(22.6 \%)$ buildings are vacant. From the overall building uses and activities, Table 1 shows three (3) identified domains subsist in the research area.

Table 1. Subsist ICH domain in the research area

\begin{tabular}{lll}
\hline Domain & Details & Justification \\
\hline Traditional craftsmanship & 20 practitioners & $\begin{array}{l}\text { All the practitioners treasure skills and knowledge in specific craftsmanship. } \\
\text { These skills are precious as they have been transmitted for generations and } \\
\text { influence the formation of community identity as well as physical } \\
\text { development. }\end{array}$ \\
\hline $\begin{array}{ll}\text { Social practice, ritual and } \\
\text { festive events }\end{array}$ & $\begin{array}{l}\text { 22 religious purpose } \\
\text { specific building }\end{array}$ & $\begin{array}{l}\text { This public and private religious purposes building proves the multicultural } \\
\text { community norm and belief that linger for hundreds of years }\end{array}$ \\
\hline $\begin{array}{l}\text { Knowledge and practice } \\
\text { concerning nature and } \\
\text { universe }\end{array}$ & 14 Traditional trade & $\begin{array}{l}\text { All of the streets in core zone embody unique identity. Throughout the } \\
\text { observation, Kg Pantai Street remains the significant identity as a trade } \\
\text { centre. The activities of 'go-down' and wholesale remains until today. }\end{array}$ \\
\hline
\end{tabular}




\subsection{Criterion 2 - indication of viability level}

For criterion 2, the analysis has narrowed down to the only effected domains. At this point criterion 2 aims to measure viability of each domain. This viability measure is to identify the ability of domains to live or to operate by themselves. To identify the level of viability, the researchers have framed six (6) questions. These questions are important to reflect the possibilities of the ICH to sustain and practice. The aspects that are significant to indicate the potential of viability are: 1) frequency of practice; 2) important level for individual; 3) important level for community; 4) potential to hands down; 5) obstacles in continuing practices and 6) current efforts to preserve. Table 2 shows a summary of frequency distribution of viability measure for two ICH domains. This indication is only significant to the practitioners of traditional craftsmanship, and knowledge and practice domains. Researchers were incapable to cover the aspects of social practice, rituals and festive events domain due to time constraints and limitations. From the overall data revealed, the issues confront by Traditional Craftsmanship domain outweigh the issues in knowledge and practice domain. The issues are;

- Irregularity of practice - Majority of Traditional Craftsmanship practitioners only practiced when requested.

- Lacking of demand and unprofitable product - Besides irregularity of practice, the data shows that the product is also less in demand. Moreover, practitioners claim that the activities are unworthy in terms of economy (unprofitable).

- Insignificant in community - They asserted that the activity is important to them, or rather very significant in their life. However, the activities appear insignificant to the community life (from the practitioner's perspective). In this regard, it demonstrates an unpleasant fact; whereas in order to ensure viability of the domain, the main factor is that it (the $\mathrm{ICH}$ ) must be treasured by the community as well. The community should feel it is valuable and significant to their life, which in this case, it portrays the opposite.

- Transmission issues - Majority of the practitioners claim that there is no possibility for them to hands down their skills to the next generation. The main reasons that could be enlightening at this section are firstly, the practitioners have no heir, and secondly, their children refused to continue with the activity.

- Capital obstacle - practitioners experience capital obstacle in continuing the activities and claim not receiving any financial aid from any agencies or local authority.

Table 2. Summary of frequency distribution of viability measures

\begin{tabular}{llll}
\hline Viability Measures & Domain & $\begin{array}{l}\text { Traditional craftsmanship } \\
(\mathrm{n} / 19)\end{array}$ & $\begin{array}{l}\text { Knowledge and practice } \\
(\mathrm{n} / 14)\end{array}$ \\
\hline \multirow{2}{*}{ Frequency of practice } & Daily & 6 & 14 \\
& Upon Request & 13 & - \\
\hline \multirow{5}{*}{ Important level for individual } & Not important & - & - \\
& Slightly important & - & - \\
& Average & 3 & 2 \\
& Important & 16 & 12 \\
\hline \multirow{5}{*}{ Important level for community } & Not important & 3 & - \\
& Slightly important & - & - \\
& Average & 14 & 14 \\
& Important & 2 & - \\
\hline \multirow{3}{*}{ Potential to hands down } & Yes & 1 & 5 \\
& No & 12 & 3 \\
\hline \multirow{2}{*}{ Obstacles in continuing practices } & Not sure & 6 & 6 \\
\hline \multirow{2}{*}{ Current efforts to preserve } & Cource & 2 & - \\
& Skills & 16 & - \\
\hline & Individual & - & - \\
\hline & Local Authority & 1 & - \\
\hline
\end{tabular}




\subsection{Criterion 3 - identification potential to safeguards}

Criterion 3 aimed to identify possibilities of the domain to sustain. The measures sets by researchers to evaluate safeguarding intensity are: 1) reasons for undertaking; 2) hereditary generation; 3) plans to change; and 4) potential to handsdown. The result shows that both domains are valuable and significant to the research area (refer Table 3). As the expertise and inheritance are from the ancestors, the activities give an impact towards their life and the identity of the research area as well. However, similar issues as to the viability aspect, is that there are also transmission issues taking place at this point. The findings for criterion 3 are:

- Skilled and Knowledgably Practitioners - Traditional Craftsmanship practitioners undertake because that is their field of expertise. Meanwhile for Knowledge and Practice Domain, hereditary is the main factor of undertaking. Due to these factors, both domains are considered as valuable and significant to the place identity as well.

- Hereditary Significant - The result shows majority (11 practitioners) of the Traditional Craftsmanship are $2^{\text {nd }}$ and $3^{\text {rd }}$ generation. The result is similar to Knowledge and Practice Domain, where all of the respondents are $2^{\text {nd }}$ and $3^{\text {rd }}$ generations inheriting the knowledge from their ancestors.

- Transmission Issue - The practitioners and respondents of both domains are optimists in continuing the practice of the activities. They have no plans to change it. However, the statistics show a very low potential to transmit. As shown in Table 4, 12 out of 19 practitioners who are certain that they will not transmit to the next generations, only one (1) practitioner is willing to transmit. The same issues confronted by the second domain in which, 3 out of 5 are hesitant in this matter.

Table 3. Summary of frequency distribution of safeguarding measures

\begin{tabular}{llll}
\hline Safeguarding Measures & Domain & Traditional craftsmanship $(\mathrm{n} / 19)$ & Knowledge and practice $(\mathrm{n} / 14)$ \\
\hline \multirow{5}{*}{ Reasons for undertaking } & Hereditary & 7 & 14 \\
& profitable & - & - \\
& Interest and hobby & 1 & - \\
& Expertise & 11 & - \\
\hline \multirow{3}{*}{ Hereditary generations } & 1 & 8 & - \\
& 2 & 8 & 8 \\
& $3>$ & 3 & 6 \\
\hline \multirow{3}{*}{ Plan to change } & Yes & 3 & - \\
& No & 15 & 14 \\
\hline \multirow{3}{*}{ Potential To Hands Down } & Not sure & 1 & \\
& Yes & 1 & 3 \\
& Not sure & 6 & 6 \\
\hline
\end{tabular}

\subsection{Criterion 4 - local community awareness}

According to criterion 4, if the state party intends to nominate the element in the Urgent Safeguarding List, the nomination must involve the community, group or individuals. The community, group or individuals should perceive and agree on the nomination of the elements. Accordingly, this point is to discover the awareness of the community on ICH elements. There are four measures of awareness that are: 1) level of ICH understanding, 2) ICH identification, 3) Identification of local ICH, and 4) awareness on research area gaining UNESCO recognition. From the 599 occupied building, only $399(49 \%)$ of the community are willing to participate in questionnaire survey, $200(24.5 \%)$ refused.

The first measurement was to discover $\mathrm{ICH}$ understanding among the community. This part also attempts to explore the community's perception on $\mathrm{ICH}$ aspect and elements. Forty-five (45) or $11.3 \%$ out of 399 respondents understand the scopes of $\mathrm{ICH}$. Nevertheless, majority does not know or are familiar with the ICH aspect and elements. In the second measures, the study found that $53(13.3 \%)$ of the respondents were able to illustrate ICH elements. However, the other respondents (346 or $86.7 \%$ ) 
could not explain it. As a third measure, the respondents were requested to identify any $\mathrm{ICH}$ that subsists in the research area. The result shows that $344(86.2 \%)$ of respondents did not perceived any local ICH in the research area. However, $32(8 \%)$ of them considered the Baba Nyonya culture as ICH element. Thirteen (13) or 3.3\% of the respondents declare that ICH in the research area is the living heritage and $10(2.5 \%)$ of the respondents illustrate traditional craftsmanship as ICH element.

The last measure was to explore community's awareness on Melaka receiving UNESCO recognition. There are 218 (54.6\%) from 399 respondents believe that the factor of the recognition is Tangible Heritage, which means the architecture of buildings in the area. In addition, $141(35.3 \%)$ of respondents do not know what contributed to the recognition. The result also appears that $38(9.5 \%)$ of respondents believe it is because of both Tangible and Intangible Cultural Heritage, and only $2(.5 \%)$ respondents think that it is due to the unique Intangible Cultural Heritage in the area that contributed to the nomination. (Refer Table 4)

Table 4. Summary of frequency distribution on local community awareness

\begin{tabular}{lll}
\hline Awareness elements & & Total \\
\hline \multirow{2}{*}{ ICH Understanding } & Yes & $45(11.3 \%)$ \\
\cline { 2 - 2 } ICH Identification & No & $354(88.7 \%)$ \\
\cline { 2 - 3 } & Yes & $53(13.3 \%)$ \\
& No & $346(86.7 \%)$ \\
\cline { 2 - 3 } Identification of Local ICH & Living Heritage & $13(3.3 \%)$ \\
& Traditional Craftsmanship & $10(2.5 \%)$ \\
& Cultural of Baba and Nyonya & $32(8 \%)$ \\
\cline { 2 - 3 } Reason of UNESCO Recognition & Don't know & $344(86.2 \%)$ \\
\cline { 2 - 3 } & Tangible cultural heritage & $218(54.6 \%)$ \\
& Intangible cultural heritage & $2(0.5 \%)$ \\
& Tangible and intangible cultural heritage & $38(9.5 \%)$ \\
& Don't know & $141(35.3 \%)$ \\
\hline
\end{tabular}

\subsection{Criterion 5 - role of state parties}

To respond to the Criterion 5, researchers targeted three (3) State Parties that are responsible within the research area as respondents. There were three (3) questions framed by researchers, the questions focussed on; 1) necessary and safeguarding measures, 2) inventory, and 3) current safeguarding effort. The results are presented as below:

- Necessary and safeguarding measures

- The respondents have similar thoughts in "safeguarding measure". They claim that they refer to the policies and regulations. There are three (3) regulations currently applied to the research area, which are: the National Heritage Act (2005) as the highest level of legislation; the Town Planning Act (act 172); and Melaka Enactment 1988, that upholds to the National Heritage Act (2005) pertaining to ICH safeguarding.

- Inventory

- Article 12 has underlined the required documentation for $\mathrm{ICH}$ by the states parties. Documentation is considered as one of the efforts to ensure the originality of identified local ICH recorded. Nevertheless, through the interview, it shows that there is no specific inventory of local ICH (within the case study area) prepared by any agencies.

- Current safeguarding effort

- As the safeguarding measure and inventories are considered mandatory to the states parties, their current effort should also be taken into account. A good effort from each agency somehow will enhance survival rate of the ICH value. All of these agencies have been organising programs such as workshop and course. These programs are an effort to boost awareness level instead of relying on policies and act since they do believe that knowledge and understanding of the society is very important. 


\section{Discussion}

\subsection{Research findings}

Table 5 is a summary of findings for all criterions as discuss in the previous section. The major findings are: 1) Three (3) major domains of $\mathrm{ICH}$ subsist; 2) The viability of dominant $\mathrm{ICH}$ is weak; 3) The dominant $\mathrm{ICH}$ has low potential to be safeguarded; 4) Minimal awareness and understanding on $\mathrm{ICH}$ by the local community; and 5) Dominant $\mathrm{ICH}$ has not established within the core zone territory.

Table 5. Summary of research findings

\begin{tabular}{|c|c|c|}
\hline Criterion & \multicolumn{2}{|l|}{ Findings } \\
\hline \multirow{7}{*}{ Criterion 1} & \multicolumn{2}{|c|}{3 major domain of ICH subsist; } \\
\hline & \multicolumn{2}{|c|}{ 1. Traditional craftsmanship domain } \\
\hline & \multicolumn{2}{|c|}{$>$ Identified 20 practitioners in 2013, 2 practitioners passed away in 2015} \\
\hline & \multicolumn{2}{|c|}{ 2. Social ritual, practices and festive domain } \\
\hline & \multicolumn{2}{|c|}{$>22$ religious and association buildings } \\
\hline & \multirow{2}{*}{\multicolumn{2}{|c|}{$\begin{array}{l}\text { 3. Knowledge and Practice Concerning Nature and Universe Domain } \\
>14 \text { traditional trades significant to past function of the Kg. Pantai Street }\end{array}$}} \\
\hline & & \\
\hline \multirow{6}{*}{ Criterion 2} & \multirow{5}{*}{5 major issues } & 1. Irregularity in practicing \\
\hline & & 2. Lack of demand and unprofitable product \\
\hline & & 3. Insignificant to the community \\
\hline & & 4. Transmission issues \\
\hline & & 5. Capital obstacle \\
\hline & Major finding & Weak viability level \\
\hline \multirow{4}{*}{ Criterion 3} & \multirow[t]{3}{*}{3 findings } & 1. Skilled and knowledgeable practitioners \\
\hline & & 2. Hereditary significant \\
\hline & & 3. Transmission issues \\
\hline & Major Finding & Low potential to safeguards \\
\hline Criterion 4 & \multicolumn{2}{|c|}{ Local community lacks awareness and understanding } \\
\hline Critarion 5 & \multirow{2}{*}{\multicolumn{2}{|c|}{$\begin{array}{l}\text { There is no specific inventory, policy, standard or regulation for } \mathrm{ICH} \text {. } \\
\text { Dominant } \mathrm{ICH} \text { has not established within the core zone territory. }\end{array}$}} \\
\hline entionso & & \\
\hline
\end{tabular}

\subsection{Status of ICH in Melaka world heritage site}

Table 6 shows the summary of all criterions. To evaluate the status of $\mathrm{ICH}$ in the research area, researcher sets up weights for each measurement of the criterions. There are three (3) stages of weight in the Quantitative Analysis. The weights are: 1) when the frequency of the measurement show below $50 \%$, it is considered as negative influence, thus the weight is one (1); 2) If the statistic shows precisely $50 \%$, its considered average, therefore, the weight score is 2.5 and 3 ) weight five (5) is for statistic that is over $50 \%$, as it is considered as positive influence.

Weights for Qualitative Analysis are also classified into three (3): 1) if majority of feedback is positive, it is marked as five (5), 2) If the majority of responses demonstrate as average, the weight is 2.5 , and 3 ) if outcome illustrated negative influence then the weight, it is marked as one (1). Table 6 shows the total score is $44.5 / 110$, which is less than half of the total marks to be considered as average (the average score is 55). Thus, the findings suggest the ICH in the Melaka World Heritage Site (MWHS) can be declared as threatened. 
Table 6. Summary of criterions

\begin{tabular}{lll}
\hline Criterion & Description & Weight \\
\hline Criterion 1 & Oral traditions and expressions & - \\
& Performing Arts & - \\
& Social Practices, rituals and festive events & 5 \\
& Knowledge and practices concerning nature and the universe; & 5 \\
& Traditional Craftsmanship & 5 \\
\hline Criterion 2 & Frequency Of Practice & 1 \\
& Important Level For Individual & 5 \\
& Important Level For Community & 2.5 \\
& Potential To Hands Down & 1 \\
& Obstacles In Continuing Practices & 1 \\
& Current Efforts To Preserve & 1 \\
\hline Criterion 3 & Reason for undertaking & 2.5 \\
& Hereditary generations & 5 \\
& Plan to change & 1 \\
& Potential To Hands Down & 1 \\
\hline Criterion 4 & ICH understanding & 1 \\
& ICH identification & 1 \\
& Identification of ICH in Territory & 1 \\
& Awareness & 1 \\
\hline Total Score & Necessary and safeguarding measure & 2.5 \\
& inventories & 1 \\
& Current effort & 1 \\
\hline Criterion 5 & & 44.5
\end{tabular}

Notes:

For quantitative analysis;

i) Statistic shows $50 \%>=5$

ii) Statistic shows $50 \%=2.5$

iii) Statistic shows $<50 \%=1$
For qualitative analysis;

i) Positive view/feedback/influence $=5$

ii) average view/feedback/influence $=2.5$

iii) Negative view/feedback/influence $=1$

\section{Conclusion and Recommendation}

This study has adapted five (5) criterions outlined by UNESCO in order to evaluate the status of ICH. These include criterion 1 (identification of $\mathrm{ICH}$ ), criterion 2 (indication of viability level), criterion 3 (identification potential to safeguards), criterion 4 (local community awareness) and criterion 5 (role of state parties). The involvement of the society and the cultural heritage as associated components are inevitable in studying the social behaviour in the case study area (MWHS).

A methodology that involves three (3) parties (i.e., practitioners, community and state parties) was developed in order to achieve the aim of the study. The result of this study shows that the $\mathrm{ICH}$ in the study area is threatened due to five (5) major uncertain behaviors of the host (i.e., the practitioners and community) which includes: 1) irregularity of practice; 2) lack of demand and unprofitable product; 3) insignificant to community; 4) transmission issues; and 5) capital obstacle. Besides, the community also shows minimal awareness and understanding on $\mathrm{ICH}$. This result appears similar to those by Bakar, Mariana, Syahriah and Mansor (2014) in their study on community involvement level in ICH on MWHS. The situation is rather worrying, when enforcement and effort by state parties to safeguard the $\mathrm{ICH}$ is still at infant stage. In order to mitigate these issues, the state parties are recommended two pursue (2) aspects. 
The first aspect is to strengthen the level of awareness and understandings in the $\mathrm{ICH}$ by establishing the dominant $\mathrm{ICH}$ in the Core Zone area. Agencies can set up research and development (R\&D) unit that focuses on the ICH within their territory. The second aspect is to improve the management and safeguarding efforts. This can be done by establishing specific policies and regulation for the $\mathrm{ICH}$ in the Core Zone area. Involvement of the community in cultural heritage management is vital and their opinions should be considered in the process of heritage protection. The state parties are also encouraged to collaborate with the community to create apprentice of the related ICH skills and knowledge.

It is suggested that further researches need to concentrate on the investigation of challenges confronted by state parties in safeguarding $\mathrm{ICH}$, and develop a proposed database of dominant $\mathrm{ICH}$ in MWHS.

\section{References}

Bakar, A. A., Mariana, M. O., Syahriah, B., \& Mansor, I. (2014). Analysis on Community Involvment Level in Intangible Cultural Heritage: Malacca cultural community. Procedia-Social Behavioral Sciences, 286-297.

Bouchenaki, M. (2003). The interdependency of the tangible and intangible cultural heritage. Zimbabwe: ICOMOS.

CAPAM. (2010). Overview of Case Study Models and Methodology. Ottawa: Commonwelth Association for Public Administration and Management.

Congdon, J. D., \& Dunham, A. E. (1999). Defining the Begining: the importance of research design. In K. L. Eckert, K. A. Bjorndal, F. A. Grobois, \& F. Donelly,

Research and management techniques for the conservation of sea turtles (pp. 83-87). Washington: IUCN/SSC Marine Turtle Specialist Group Publication. ICOMOS. (2008). Evaluations of Cultural Poperties . Canada: UNESCO.

Johnson, R. B., Onwuegbuzie, A. J., \& Turner, L. A. (2007). Toward a Definition of Mixed Methods Research. Journal of Mixed Methods Reseach, 112-133.

Munjeri, D. (2004). Tangible and Intangible Heriatge: from difference to covergence. Museum International, 13-20.

othman, R. N., \& Hamzah, A. (2013). Interdependency of Cultural Heritage Assetes in Old Quater, Melaka Heritage City. Procedia-Social and Behavioral Sciences, 577-588.

Powell, E. T., \& Steele, S. (n.d.). Collecting evalutaion Data: Direct Observation. Retrieved May 14, 2014, from http://learningstore.uwex.edu/assets/pdfs/g36585.pdf

Remenyi, D. (2011). Field methods for academic research - interviews, focus group and questionnaires. United Kingdom: Ridgeway Press .

Simon, M. K., \& Goes, J. (n.d.). Scope, limitations and delimitations. Retrieved January 13, 2013, from www.dissertationrecipes.com

Szolnoki, G., \& Hoffman, D. (2013). Online, Face - to - face and telephone surveys: Comparing different sampling methods in wine consumer research. Wine Economy and Policy, 2 , 57-66.

UNESCO (2009). List of Intangible in Need of Urgent Safeguarding. Canada: UNESCO. 